Research Article

\title{
Study on Breakdown Probability of Multimaterial Electrodes in EDM
}

\author{
Y. Liu $\mathbb{D}^{1},{ }^{1}$ W. Wang, ${ }^{1}$ W. Zhang $\mathbb{D},{ }^{1}$ F. Ma, ${ }^{1}$ Y. Wang, ${ }^{2}$ B. Rolfe, ${ }^{2}$ and S. Zhang $\mathbb{D}^{1}$ \\ ${ }^{1}$ School of Mechanical Engineering, Dalian Jiaotong University, Dalian 116028, China \\ ${ }^{2}$ School of Engineering, Deakin University, Geelong, VIC 3220, Australia \\ Correspondence should be addressed to S. Zhang; zsf@djtu.edu.cn
}

Received 31 August 2017; Accepted 6 February 2018; Published 27 March 2018

Academic Editor: Frederic Dumur

Copyright (c) 2018 Y. Liu et al. This is an open access article distributed under the Creative Commons Attribution License, which permits unrestricted use, distribution, and reproduction in any medium, provided the original work is properly cited.

With the development of EDM technology, some multimaterial electrodes which have some special functions are regularly taking the place of traditional single material electrodes on some machining occasions and becoming widely used. In this paper, the influence of material on discharge breakdown in EDM with multimaterial electrodes is studied. A comparison model about material influence on discharge breakdown under both single discharge condition and continuous discharge condition is established, and the material property factors affecting the probability of discharge breakdown are also analyzed. Finally, a series of experiments are carried out to study the effects of different electrode materials on the discharge breakdown of EDM, a fitting formula of breakdown probability is presented, and the effectiveness of the comparison model is also verified by comparing with experimental results.

\section{Introduction}

Electrical discharge machining (EDM) is a commonly used nontraditional machining method, which can be used to process difficult-to-cut materials and parts that feature with complex shapes. It is widely used in small hole and cavity machining of mold production. With the continuous development of mold manufacturing technology, the die cavity is developing towards the direction of more complexity and precision, and conventional single material EDM electrodes have been difficult to meet the diverse requirements of cavity structure and die accuracy [1]. In addition, for different processing features, such as plane and hole, different electrode materials can meet the requirements of accuracy and surface quality of the corresponding features in one single processing, thus improving the efficiency of forming process. Therefore, some multimaterial electrodes which have some special functions are increasingly replacing traditional single material electrodes in some machining processes.

Extensive researches have been carried out on EDM with multimaterial electrodes. Mohri et al. presented a new method of surface modification by EDM using the composite structured electrode. Copper, aluminum, tungsten carbide, and titanium were used for the materials of the electrode. It was revealed that surfaces after modification have less cracks and higher corrosion resistance and wear resistance [2]. Uhlmann and Roehner aiming to decrease the wear of tool electrodes used boron-doped CVD (B-CVD) diamond and polycrystalline diamond (PCD) as electrode materials for micro-EDM, and experimental investigations on PCD and B-CVD diamond as tool electrode materials showed good results with respect to wear and process behavior under process conditions of micro-EDM [3].

Aiming at the problem that the rate of material removal decreases rapidly in EDM with the increase of processing depth, Cao et al. made some $\mathrm{Cu}-\mathrm{Cr}$ composite electrodes and did EDM experiments with brass electrodes and $\mathrm{Cu}-\mathrm{Cr}$ composite electrodes. The removal rate and processing quality of different electrode materials were compared and analyzed. It was found that the removal rate of the composite electrode material was improved by about 2 times, and the machining accuracy was improved significantly too [4]. Tsai et al. proposed a new method of blending copper powders with resin and chromium powders to make composite 
electrodes. It has shown that the composite electrodes obtained can achieve a higher material removal rate (MRR) than copper electrodes, the recast layer is thinner, and fewer cracks are present on the machined surface [5]. Khanra et al. developed a metal matrix composite $\left(\mathrm{Cu}-\mathrm{ZrB}_{2}\right)$ to get an optimum combination of wear resistance and electrical and thermal conductivity. The $\mathrm{Cu}-\mathrm{ZrB}_{2}$ composite was developed by adding different amounts of $\mathrm{Cu}$ and tested as an electrode material at various process parameters of EDM during machining of mild steel. It was found that the $\mathrm{ZrB}_{2}$ 40 wt.\% $\mathrm{Cu}$ composite shows more MRR with less tool removal rate (TRR) than commonly used $\mathrm{Cu}$ tool [6]. ElTaweel investigated the relationship between process parameters in electrodischarge of CK45 steel and tool electrode material as $\mathrm{Al}-\mathrm{Cu}-\mathrm{Si}-\mathrm{TiC}$ composite is produced using powder metallurgy $(\mathrm{P} / \mathrm{M})$ technique. The central composite second-order rotatable design had been utilized to plan the experiments, and response surface methodology (RSM) was employed for developing experimental models. $\mathrm{Al}-\mathrm{Cu}-\mathrm{Si}-\mathrm{TiC} \mathrm{P} / \mathrm{M}$ electrodes are found to be more sensitive to peak current and pulse on-time than conventional electrodes [7]. Senthilkumar and Reddy developed a new copper-based metal matrix composite $\left(\mathrm{Cu}-\mathrm{B}_{4} \mathrm{C}\right)$ for an $\mathrm{EDM}$ electrode to get an optimum combination of wear resistance and electrical and thermal conductivity. The results showed that copper composite with $40 \%$ boron carbide reinforcement exhibited better MRR and TRR compared to the conventional copper electrode [8].

Anil and Çoğun, from the experimental study, observed and compared the performance of solid copper and coppercoated stereo lithography (CC/SLA) electrode. It was found that the internal cooling channel formed by SLA technology prolongs the life of the CC/SLA electrode by dissipating the heat of coating [9]. Wang et al., through composite electroplating technology, electrodeposited $\mathrm{Cu}-\mathrm{ZrB}_{2}$ composite coating on the side of composite electrode they made for experiments. It was concluded that the $\mathrm{Cu}-\mathrm{ZrB}_{2}$ composite coating can improve the electrical erosion resistance of the electrode and can effectively guarantee the uniform wear of the end face of the electrode and reduce the tapering of the machined hole [10]. Lv studied the machining process of micro-EDM with composite electrodes by means of computer simulation. The $\mathrm{Cu}$-based $\mathrm{Ni}-\mathrm{W}$ alloy composite electrode was fabricated by the electroplating method for EDM experiments. The electrical erosion resistance of the surface material is enhanced, and the sidewall wear of the electrode can be effectively reduced, and the shape accuracy of the machined hole can be greatly improved [11]. Li et al. studied the wear mechanism of the Ni-TiN/Cu composite electrode in the case of high-frequency pulse current and found out the influence of the fluctuation frequency of discharge current on electrode wear in micro-EDM. It is shown that, compared with the electrodes made from homogeneous materials, the high-frequency electromagnetic properties of the Ni-TiN composite layer can be used effectively to inhibit the skin effect of high-frequency pulse on the electrode and improve the distribution trend of current density [12]. Yuangang et al. made the $\mathrm{Cu}-\mathrm{ZrB}_{2}$ composite coating electrodes by way of the electrode position process

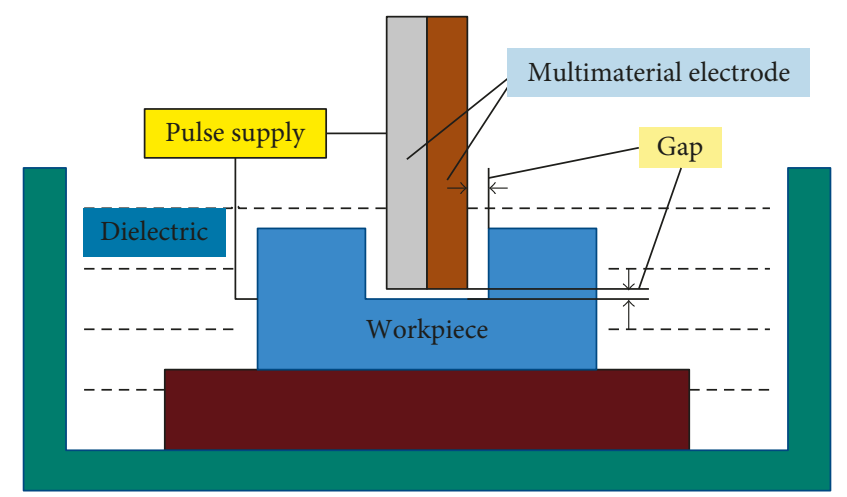

Figure 1: Machining process of EDM with multimaterial tool.

on the basis of the difference between the discharging performance of the electrodeposited coating and that of the matrix to ensure uniform wear of electrode bottom faces. Compared with the conventional electrodes, $\mathrm{Cu}-\mathrm{ZrB}_{2}$ composite coating electrodes display better wear resistance on the same experimental conditions [13]. Chiou et al. presented a comparative study of the performance of WC, WC-coated Ag, and WC-coated Cu electrodes for the microEDM milling, and the experimental results showed that the WC-coated Ag electrodes yielded the lowest surface roughness and the $\mathrm{WC}$-coated $\mathrm{Cu}$ electrodes achieved the highest material removal rate, which illustrated the effectiveness of the electrode coating method [14].

Based on the above research, we can find that although a great deal of achievements have been made in the research about EDM with multimaterial electrodes, the related researches only stay at the level of technologic experiments. The discharge mechanisms of EDM with multimaterial electrode, such as the influence mechanism of multimaterials on the distribution of discharge breakdown and the law of distribution, absorption, and conduction of discharge energy in multiphase materials, and the mechanism of ejection process of multiphase molten metal materials, are still not very clear. This paper carries out the theoretical analysis and experimental verification about the breakdown probability of the multimaterial electrode in $\mathrm{EDM}$, and relevant research results can provide a reference for further analysis of EDM mechanism with multimaterial electrodes.

\section{Breakdown Process Analysis of Multimaterial Electrode}

EDM is a kind of nontraditional machining method that uses spark discharge to breakdown the dielectric between poles of extremely close distance and removes the electrode material by way of thermal effect of breakdown. The machining process of EDM with multimaterial tool is shown in Figure 1. Substantially, the discharge breakdown process of EDM is affected directly by the thermal field electron emission of cathode electrons. After the thermal field electron emission, under the effect of high-strength electric field, the electron avalanche ionizations are generated in the interelectrode 
dielectric; when the electron avalanche ionizations reach the anode, the dielectric is broken down and the discharge channel is formed. Therefore, in the early stage of the discharge breakdown process, the amount of thermal field electron emission of cathode electrons at a certain location can directly affect the probability of discharge breakdown at that location. And the amount of thermal field electron emission is characterized by thermal field electron emission current density. That is to say, the position with large thermal field electron emission current density has the high probability of discharge breakdown.

2.1. Single Discharge Breakdown Process. According to the thermal field electron emission theory, when the temperature on the tool surface is $T$ (unit $\mathrm{K}$ ), and a strong electrical field with the electric field intensity $E(\mathrm{~V} / \mathrm{cm})$ is exerted between electrodes, the current density of cathode electron emission $j$ is given as [15]

$$
j(T)=N(T) \cdot j(0),
$$

where $j(T)$ is the current density of field electron emission while temperature is $T\left(\mathrm{~A} / \mathrm{cm}^{2}\right)$, and $N(T)$ is the coefficient of correction when temperature is $T(\mathrm{~K})$ relative to when temperature is $0 \mathrm{~K}$, which is given as

$$
N(T)=\frac{Q}{\sin (Q)},
$$

where

$$
Q=2.77 \times 10^{4} \frac{T \sqrt{\phi}}{E},
$$

where $\phi$ is the electron work function $(\mathrm{J})$ and $j(0)$ is the current density of field electron emission while temperature is $0 \mathrm{~K}\left(\mathrm{~A} / \mathrm{cm}^{2}\right)$, which can be expressed as

$$
\begin{aligned}
j(0)= & \frac{1.54 \times 10^{-6} E^{2}}{\phi} \\
& \cdot \exp \left[-\frac{6.83 \times 10^{7} \phi^{3 / 2}}{E} \theta\left(3.39 \times 10^{-4} \frac{\sqrt{E}}{\phi}\right)\right],
\end{aligned}
$$

where $\theta(y)$ is the Nordheim function.

As to different materials, copper and iron $(\mathrm{Fe})$, for example, we set the same electron emission conditions, $T=$ $300 \mathrm{~K}$ and $E=4 \times 10^{7} \mathrm{~V} / \mathrm{cm}$, when the Nordheim function $\theta(y)$ is approximately equal to 1 ; then among all the parameters in (1)-(4), only electron work function $\phi$ is different between these two materials while the rest of them are all the same. Electron work function of common metals is shown in Table $1[16]$.

Based on the thermal field electron emission theory, the field electron emission current density can be used to characterize the breakdown probability. Where the thermal field electron emission current density is large, it is easier to form discharge breakdown, and further the breakdown probability increases. A ratio coefficient of breakdown probability $R_{\mathrm{p}}$ is used to characterize the numerical comparison of thermal field electron emission current density of different
TABLE 1: Electron work function of common metals [16].

\begin{tabular}{lc}
\hline Materials & Electron work function, $\phi(\mathrm{eV})$ \\
\hline Copper & 5.24 \\
Brass & $3.34-5.24$ \\
Zinc & 3.34 \\
Iron & 4.47 \\
Copper-tungsten alloy & $4.54-5.24$ \\
Tungsten & 4.54 \\
\hline
\end{tabular}

electrode materials. The ratio coefficient of breakdown probability $R_{\mathrm{p}(\mathrm{Fe}-\mathrm{Cu})}$ is

$$
R_{\mathrm{p}(\mathrm{Fe}-\mathrm{Cu})}=\frac{j(T)_{\mathrm{Fe}}}{j(T)_{\mathrm{Cu}}} .
$$

By substituting the electron work function of copper and iron as $5.24 \mathrm{eV}$ and $4.47 \mathrm{eV}$ into (1)-(4) and comparing, we can get that $j(0)$ of copper and iron is approximately equal and $N(T)$ of copper and iron is also approximately equal; therefore, the thermal field electron emission current density of the two is approximately equal, which means the influence of different materials on the breakdown process is basically the same.

\subsection{Effect of Continuous Discharges on Breakdown}

Process. For continuous spark discharges, the change of discharge environment caused by the previous breakdown process can lead to next breakdown process occurring near the previous breakdown discharge channel [17]. The two factors which have the most influence on the breakdown process are the dielectric's properties and the change of the temperature around the discharge channel. However, the change of dielectric property is mainly related to the dielectric deionization ability and the distribution of the debris interelectrodes, which has little relationship with the electrode material, so it will not be discussed here. The change of the temperature around the discharge channel is mainly due to the electric heating effect of the plasma caused by the previous breakdown (the temperature of the central region of the discharge channel can reach above $10,000 \mathrm{~K}$ ); even during the material removal process, part of the heat is taken away by the debris and the dielectric; the temperature of the material in the discharge crater can still be several thousand degrees. And during the pulse interval, the temperature at crater decreases due to thermal conduction. The following equation is the Fourier thermal conduction law:

$$
d Q=-\lambda \frac{\partial T}{\partial n} d A d t
$$

where $Q$ is the amount of heat conducted $(J), \lambda$ is the thermal conductivity of the material $(\mathrm{W} / \mathrm{mK}), \partial T / \partial n$ is the temperature gradient, $A$ is the heat conduction area $\left(\mathrm{m}^{2}\right)$, and $t$ is the heat conduction time (s). And the relationship equation between the amount of heat conduction $Q$ and temperature change $\Delta T$ is given by

$$
Q=\Delta T c \rho V
$$

where $c$ is the specific heat capacity of material $(\mathrm{J} / \mathrm{kg} \cdot \mathrm{K}), \rho$ is the density of material $\left(\mathrm{kg} / \mathrm{m}^{3}\right)$, and $V$ is the volume of material $\left(\mathrm{m}^{3}\right)$.

Supposed that two different materials have the same crater size and the same temperature gradient and the changes of 
TABle 2: Physical parameters of common metals [18].

\begin{tabular}{lccc}
\hline Materials & Density $\left(\mathrm{g} / \mathrm{cm}^{3}\right)$ & Specific heat capacity $\left(\mathrm{J} /\left(\mathrm{kg} \cdot{ }^{\circ} \mathrm{C}\right)\right)$ & Thermal conductivity $(\mathrm{W} /(\mathrm{mk}))$ \\
\hline Copper & 8.93 & 386 & 381 \\
Iron & 7.87 & 444 & 80 \\
Brass (Zn35) & 8.50 & 377 & 118 \\
Copper-tungsten alloy (W70) & 14.10 & 207 & 220 \\
\hline
\end{tabular}

thermal conductivity and specific heat capacity of the materials are very small with the temperature, the conduction time is pulse interval time, and then from (6) and (7), the ratio of temperature difference before and after the heat conduction near the discharge crater of copper and iron $R_{\Delta T(\mathrm{Cu}-\mathrm{Fe})}$ is given as

$$
R_{\Delta T(\mathrm{Cu}-\mathrm{Fe})}=\frac{\Delta T_{\mathrm{Cu}}}{\Delta T_{\mathrm{Fe}}}=\frac{\lambda_{\mathrm{Cu}}}{\lambda_{\mathrm{Fe}}} \cdot \frac{c_{\mathrm{Fe}} \rho_{\mathrm{Fe}}}{c_{\mathrm{Cu}} \rho_{\mathrm{Cu}}} .
$$

From Table 2 [18], the value of (8) can be calculated as 4.83 , which indicates that the decrease of temperature due to heat transfer in the discharge region of copper material is about 5 times that of the discharge region of the iron material because the thermal conductivity of the copper material is higher than that of the iron material. For the discharge region with an initial temperature of $3500 \mathrm{~K}$, if the temperature of the iron material electrode is decreased by heat transfer of $200 \mathrm{~K}$, then the cooling of the copper material electrode will reach about $1000 \mathrm{~K}$. At the same time, due to the difference of the temperature in the discharge region, the value of the temperature correction coefficient $N(T)$ will be changed accordingly, and then the difference of the thermal field emission current $j(T)$ is significant. The thermal field emission current $j(T)$ is given as [19]

$$
\begin{aligned}
j(T)= & \frac{4 \pi e m k T}{h^{3}} \int \exp \left(-c+\frac{E_{\mathrm{e}}-E_{\mathrm{F}}}{d}\right) \\
& \cdot \ln \left(1+\exp \left(-\frac{E_{\mathrm{e}}-E_{\mathrm{F}}}{k T}\right)\right) d E_{\mathrm{e}}
\end{aligned}
$$

where $e$ is the electron charge, $m$ is the electron mass, $k$ is the Boltzmann constant, $h$ is the Planck constant, $E_{\mathrm{e}}$ is the energy of the electron, and $E_{\mathrm{F}}$ is the Fermi energy. By substituting the aforementioned known parameters, from logarithm table of current density as shown in Table 3, it can be seen that the thermal conductivity of iron is poor so that it is not easy to conduct heat away from discharge region, and as a result, the temperature is high, which leads to the thermal field emission current density of the iron electrode $\left(j(T)_{\mathrm{Fe}}\right)$ 53.7-83.2 times that of the copper electrode $\left(j(T)_{\mathrm{Cu}}\right)$ under the same conditions. That is to say, the ratio coefficient of breakdown probability $R_{\mathrm{p}(\mathrm{Fe}-\mathrm{Cu})}$ is $53.7-83.2$.

Therefore, under the same discharge conditions, the iron electrode is more prone to breakdown than copper one after the continuous pulse discharges. Table 4 shows the calculation results of the ratio of temperature difference $\Delta T_{\mathrm{Cu}} / \Delta T_{i}$ and the ratio of thermal field electron emission current density $j(T)_{i} / j(T)_{\mathrm{Cu}}$ of different materials under the conditions when the initial temperature is $3500 \mathrm{~K}$ and the temperature drop by heat transfer is $200 \mathrm{~K}$. From Table 4, it can be seen that under the same conditions the thermal field emission current density of brass is the highest, that is,
TABLE 3: Logarithm value of current density under different conditions $(\lg j)[19]$.

\begin{tabular}{cccccc}
\hline$\varepsilon(\mathrm{V} / \mathrm{cm})$ & \multicolumn{5}{c}{$T(\mathrm{~K})$} \\
& 1500 & 2000 & 2500 & 3000 & 3500 \\
\hline$\phi=4.0 \mathrm{eV}$ & & & & & \\
$2 \times 10^{7}$ & 1.72 & 3.43 & 4.64 & 5.46 & 6.05 \\
$4 \times 10^{7}$ & 5.72 & 6.11 & 6.56 & 6.98 & 7.35 \\
\hline$\phi=4.5 \mathrm{eV}$ & & & & & \\
$2 \times 10^{7}$ & -1.46 & 2.20 & 3.64 & 4.63 & 5.38 \\
$4 \times 10^{7}$ & 4.53 & 5.01 & 5.61 & 6.17 & 6.65 \\
\hline$\phi=5 \mathrm{eV}$ & & & & & \\
$2 \times 10^{7}$ & -1.63 & 0.91 & 2.63 & 3.78 & 4.63 \\
$4 \times 10^{7}$ & 3.28 & 3.87 & 4.63 & 5.34 & 5.99 \\
\hline
\end{tabular}

61.7-87.1 times that of copper; as to the copper-tungsten alloy, it is 10.5-16.2 times that of copper. This means the effects of different materials on the breakdown process of continuous discharges differ significantly. A large amount of thermal field emission current density leads to the high probability of breakdown; under the same conditions, brass has the highest probability of breakdown, iron takes the second place, followed by the copper-tungsten alloy, and copper has the least probability of breakdown.

\section{EDM Experiment of Multimaterial Electrode}

3.1. Experiment Conditions. The equipment used in the experiment is a self-built EDM lathe, which mainly consists of automatic feeding device, power box, and worktable. Its spindle speed is $0.1 \mathrm{~m} / \mathrm{s}$, and it can be adjusted adaptively according to the discharge condition to meet the processing requirements under different working conditions and to prevent arc discharge. The EDM sinking machining method is adopted, and deionized water is used as the working fluid. The processing parameters of multimaterial electrodes for EDM are shown in Table 5.

The multimaterial electrodes are formed by connecting the cylindrical electrodes of two different materials in parallel, and the ends of multimaterial electrodes are polished to be very smooth. The fabricated multimaterial electrodes are shown in Figure 2. A series of continuous pulse discharge experiments are performed on a range of combinations of multimaterial electrodes, twice more repeated experiments are conducted for each electrode combination, and then the electrode end faces are observed with a high-power electron microscope, and the distribution of the discharge craters is recorded.

3.2. Experimental Results and Analysis. Figures 3-5 show the experimental results of different multimaterial electrodes of iron and copper, brass and copper, and copper-tungsten and 
TABLE 4: Calculation results of $R_{\Delta T(\mathrm{Cu}-i)}$ and $R_{\mathrm{p}(i-\mathrm{Cu})}$ of different materials.

\begin{tabular}{lcc}
\hline & $R_{\Delta T(\mathrm{Cu}-i)}\left(\Delta T_{\mathrm{Cu}}\right) / \Delta T_{i}$ & $R_{\mathrm{p}(i-\mathrm{Cu})}\left(j(T)_{i} / j(T)_{\mathrm{Cu}}\right)$ \\
\hline Iron & 4.83 & $53.7-83.2$ \\
Brass (Zn35) & 3.00 & $61.7-87.1$ \\
Copper-tungsten & 1.47 & $10.5-16.2$ \\
alloy (W70) & & \\
\hline
\end{tabular}

TABle 5: Processing parameters of multimaterial electrodes for EDM.

\begin{tabular}{|c|c|}
\hline Items & Parameters \\
\hline Workpiece material & Die steel \\
\hline Multimaterial electrodes & $\begin{array}{c}\text { Iron and copper; copper and } \\
\text { copper-tungsten; brass and copper }\end{array}$ \\
\hline Machining polarity & Normal \\
\hline $\begin{array}{l}\text { Thickness of workpiece } \\
(\mathrm{mm})\end{array}$ & 4 \\
\hline Pulse on time, $T_{\text {on }}(\mu \mathrm{s})$ & 12.5 \\
\hline Pulse interval time, $T_{\text {off }}(\mu \mathrm{s})$ & 7.5 \\
\hline Breakdown voltage, $U_{\mathrm{b}}(\mathrm{V})$ & 45 \\
\hline Peak current, $I_{\mathrm{p}}(\mathrm{A})$ & 0.8 \\
\hline $\begin{array}{l}\text { Diameter of cylindrical } \\
\text { electrode }(\mathrm{mm})\end{array}$ & 2 \\
\hline Machining time, $t(\mathrm{~s})$ & 3.0 \\
\hline Dielectric & Deionized water \\
\hline
\end{tabular}

copper, respectively. From the figures we can see that, under the same conditions of discharge, the number of craters on iron electrodes is more than that on copper ones, and similarly, the number of craters on brass electrodes is more than that on copper ones, and the craters on copper-tungsten electrodes are more than those on copper ones.

As can be seen from Figure 3, for the same discharge breakdown condition, the discharge points are mostly distributed on the surface of the iron electrode at the end of discharge, and only a few discharge points exist on the surface of the copper electrode. This shows that the breakdown probability of iron is obviously higher than that of copper. It can also be found that the thermal conductivity of iron is much smaller than that of copper, which indicates that after continuous discharge, because of the low thermal conductivity of iron, less heat is transmitted from the iron to the outside. Meanwhile, as the specific heat capacity of iron is higher than that of copper, iron of the same temperature as copper contains more heat, and the temperature reduction of the iron is also smaller. The temperature of the iron electrode surface is higher than that of the copper electrode, which promotes the emission of the cathode thermal field electron emission on the electrode surface; therefore the breakdown probability of the iron electrode is elevated. The high-temperature burn traces on the surface of the iron electrode from Figure 3(a) can also demonstrate the presence of high temperature on the surface of the electrode after continuous discharges.

As can be seen from Figure 4, a large number of discharge points can be found on the surfaces of both copper and brass electrodes, and the discharge points on the surface of the brass electrode are much more than those of the copper surface, although the difference between the two is not as large as the

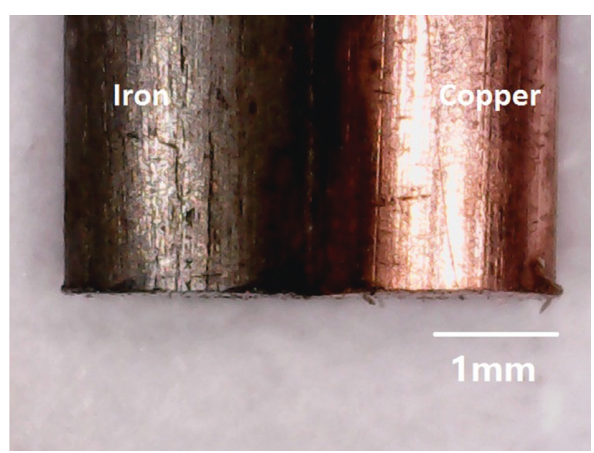

(a)

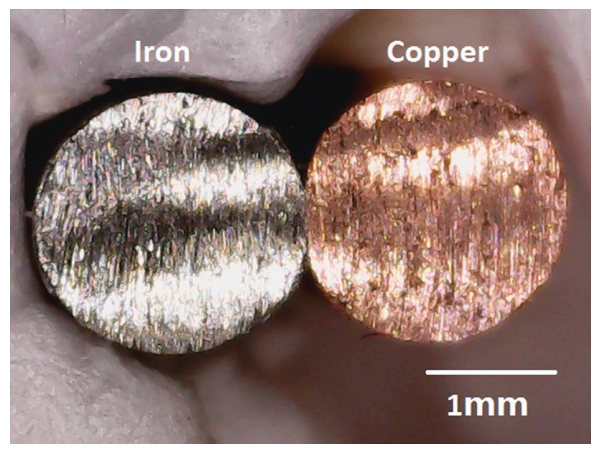

(b)

FIGURE 2: Fabricated multimaterial electrodes of iron and copper. (a) Side view. (b) Bottom view.

difference between copper and iron electrodes. This is because the conductivity of brass is slightly better than iron, and its specific heat capacity is similar to that of copper; under continuous discharge conditions, the temperature difference between the left and the right of the multimaterial electrode is not as large as the copper-iron electrode; therefore, the difference of discharge points decreases.

From Figure 5, it is noted that although the discharge points of the copper-tungsten alloy electrode are more than those of the copper electrode, the difference between them is obviously reduced compared with Figures 3 and 4. This is because, although the thermal conductivity of copper-tungsten alloy is smaller than that of copper, its specific heat is smaller than that of copper too; these two aspects have the same effect on the temperature difference of heat conduction. The reason why the breakdown probability of copper-tungsten alloy is higher than that of copper is probably because the density of coppertungsten alloy is greater, which can increase the amount of heat contained in the same volume of material and make up for the deficiency of smaller specific heat capacity. And because the thermal conductivity of copper-tungsten alloy is lower than that of copper, the surface temperature of copper-tungsten alloy material is higher, so its breakdown probability is increased.

3.3. Experimental Data Processing. We quantitatively describe the number of discharge craters distributed on different electrodes by using the discharge affecting area on electrode surface which can be calculated by pixel analysis function of image processing software Matlab. The pixel analysis method is a method of using the image processing 


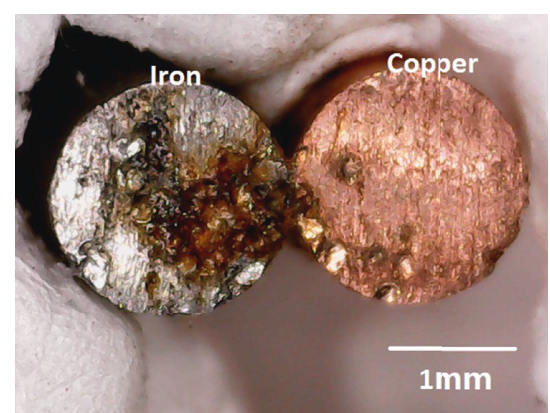

(a)

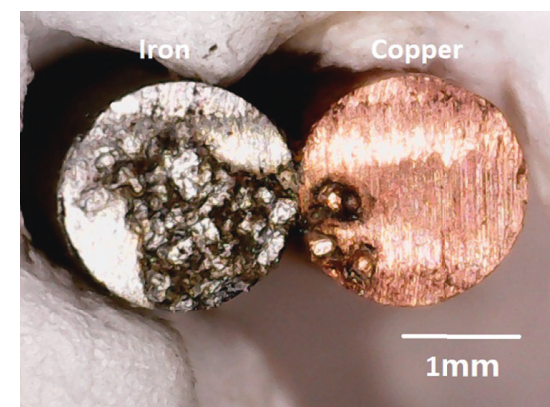

(b)

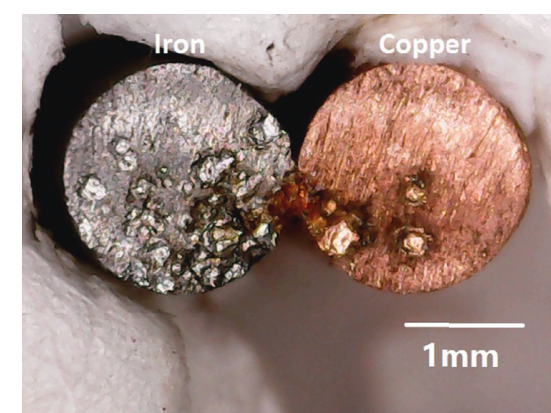

(c)

FIGURE 3: Discharge point distribution on the surface of iron and copper electrodes.

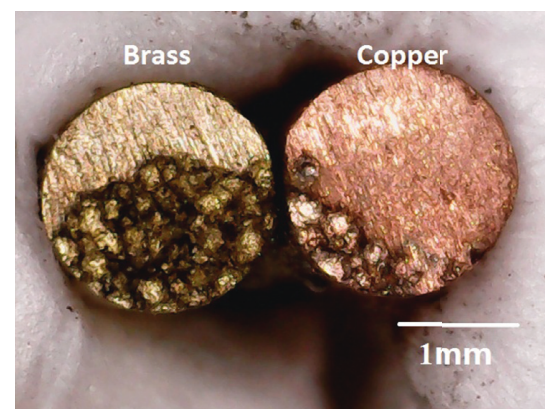

(a)

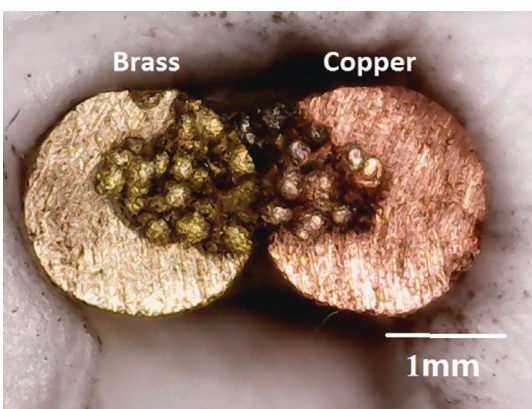

(b)

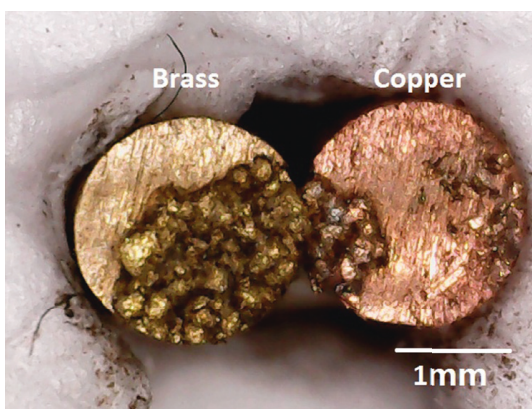

(c)

FIGURE 4: Discharge point distribution on the surface of brass and copper electrodes.

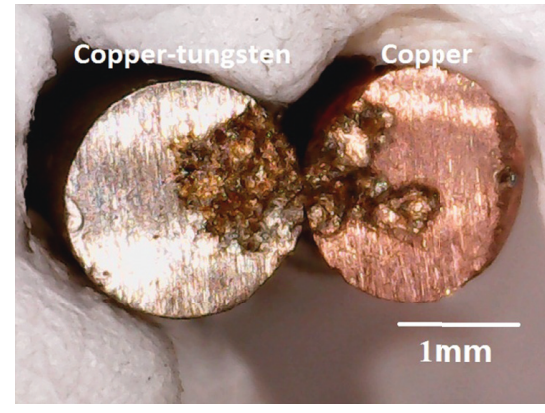

(a)

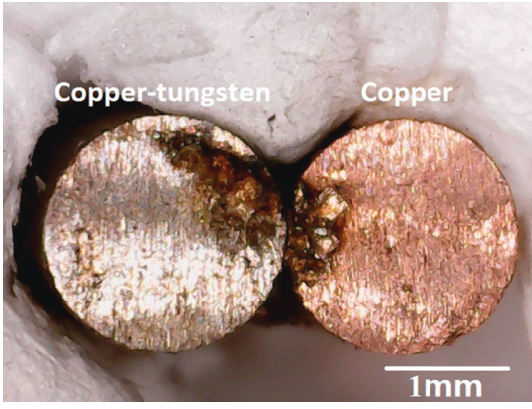

(b)

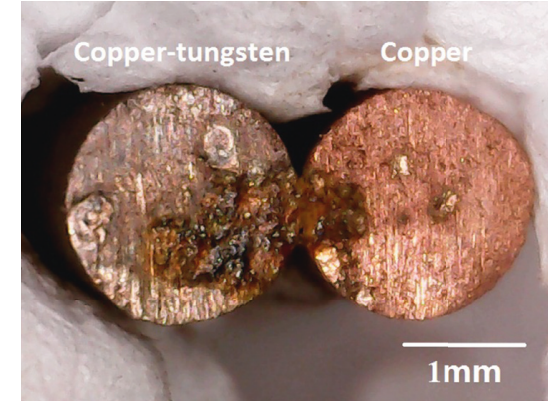

(c)

FIGURE 5: Discharge point distribution on the surface of copper-tungsten and copper electrodes.

software to accurately analyze the area of an irregular image. It utilizes proportion relation between image pixels and image area in the same photo, by calculating the display pixels of testing image, to analyze the actual area of testing image. According to the proportion relation between the image pixel and the actual area, an equation is given by

$\frac{\text { testing area }(\mathrm{At})}{\text { reference area }(\mathrm{Ar})}=\frac{\text { display pixels of testing area }(\mathrm{Pt})}{\text { display pixels of reference area }(\mathrm{Pr})}$.

When analyzing the discharge affecting area, the reference area $\mathrm{Ar}$ is the known quantity, as the diameter of the cylindrical electrode in the machining process is $2 \mathrm{~mm}$; for ease of calculation, a square with the side length of $2 \mathrm{~mm}$ is taken as a reference image, then the reference area is $4 \mathrm{~mm}^{2}$; the display pixels of reference area $\operatorname{Pr}$ are the known quantity and it is the corresponding pixels of the reference area in the image processing software. The display pixels of testing area Pt are the pixels corresponding to discharge affecting area selected in the figure. The discharge affecting areas differ on different electrode surfaces, and the display pixels of testing area are different. Therefore, by obtaining the display pixels of testing area in the software, substituting the known quantities of reference area and the display pixels of reference area, the discharge affecting area on electrode surface can be calculated accurately from (10). The discharge 


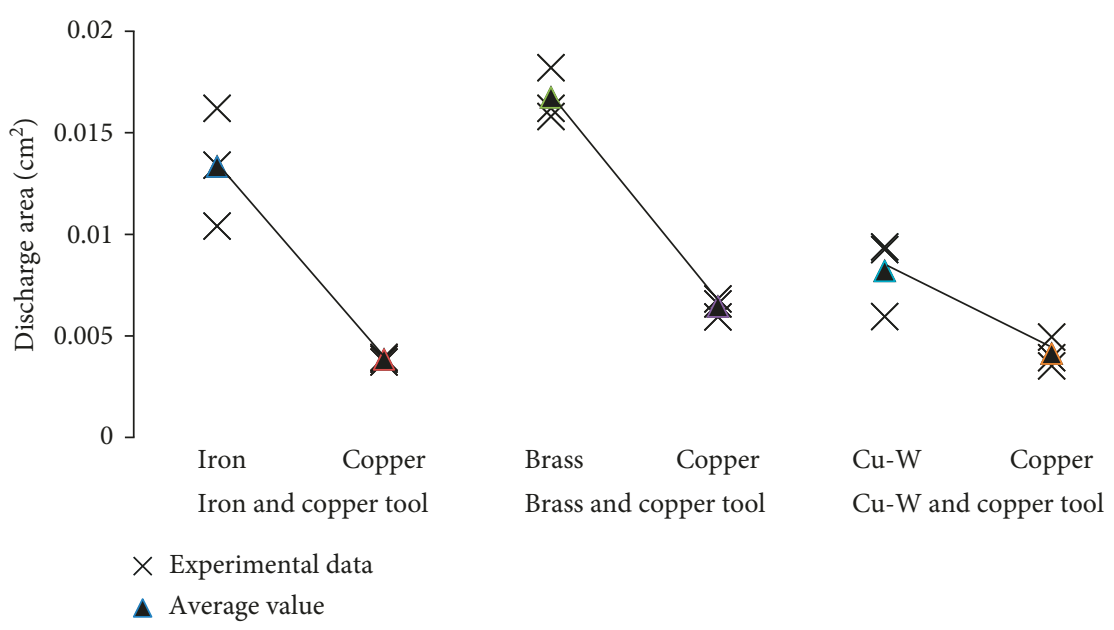

FIGURE 6: Discharge area on the surface of different multimaterial tools.

affecting areas on the surface of different multimaterial electrodes are calculated as shown in Figure 6.

As can be seen from Figure 6, the discharge point areas from large to small are followed by brass, iron, coppertungsten alloy, and copper. The discharge point area of copper is the smallest in each set of data, and the discharge point areas of brass, iron, and copper-tungsten alloy are of several-fold relation with that of copper. This is because the thermal conductivity of copper is greater than that of other materials, and its specific heat capacity is the smallest so that it has the minimum breakdown probability, and this corresponds well with the previous analysis results of the ratio coefficient of breakdown probability. On the end face of the iron and copper tool, the average discharge area on iron surface is 3.5 times as that on copper surface. On the brass and copper tool, the average discharge area on brass surface is 2.6 times as that on copper surface. The reason for the reduction of area difference is that the discharge area of the copper surface is increased. While on the copper-tungsten and copper tool, the average discharge area ratio is less than 2 . The difference in the breakdown probability of copper between iron, brass, and copper-tungsten alloy decreases gradually. This is because the thermal conductivity of iron is smaller than that of other materials, and the specific heat capacity is greater than that of other materials so that it has the maximum breakdown probability with copper. Besides, the thermal conductivity of copper-tungsten alloy is the largest among those materials, and its specific heat capacity is the smallest; therefore, the difference in the breakdown probability compared with copper is the smallest among the three materials. In addition, it can also be seen from Figure 6 that the discharge area of the brass and copper tool is larger than that of the other two groups overall, and this may be due to the low electron work function of zinc in brass, which is helpful to improve the occurrence rate of discharge breakdown, increasing the number of discharges on the brass surface. At the same time, due to the influence of the discharge breakdown, the number of discharges on the surface of copper is also increased.

According to the experiment results, breakdown probability of different materials compared with copper $P_{\mathrm{b}(i-\mathrm{Cu})}$ can be obtained as

$$
P_{\mathrm{b}(i-\mathrm{Cu})}=\frac{\text { Testing area of material } i\left(A_{i}\right)}{\text { Testing area of material } i\left(A_{i}\right)+\text { testing area of copper }\left(A_{\mathrm{Cu}}\right)}
$$

Based on the experiment results of breakdown probability as well as the ratio of temperature difference $R_{\Delta T(\mathrm{Cu}-i)}$ and the ratio coefficient of breakdown probability $R_{\mathrm{p}(i-\mathrm{Cu})}$, formulary fitting is carried out by the adaptive fit method using Matlab, and the breakdown probability fitting formula of different materials compared with copper is given as

$$
\begin{aligned}
P_{\mathrm{b}(i-\mathrm{Cu})}= & 0.7658+0.07448 \sin \left(\pi \cdot R_{\Delta T(\mathrm{Cu}-i)} \cdot R_{\mathrm{p}(i-\mathrm{Cu})}\right) \\
& -0.269 \exp \left(-\left(0.1093 R_{\mathrm{p}(i-\mathrm{Cu})}\right)^{2}\right) .
\end{aligned}
$$

From (12), the exact breakdown probability of certain material compared to copper can be obtained, and further, the breakdown probability between any two different materials can also be obtained.

The proposed model in this paper has the ability to analyze and predict the electrode discharge breakdown probability of different materials, and the reasons for the different breakdown probabilities of different materials are given with a reasonable explanation by the model, which is of some significance for the understanding of discharge mechanism of EDM. 


\section{Conclusions}

In this paper, the influence law of surface breakdown probability of multimaterial electrodes is analyzed according to the theory of field electron emission, a mathematical model of material property influencing discharge breakdown in interelectrodes is established, the model is verified by experimental method, and the conclusions are drawn as follows:

(1) In single pulse discharge process, the breakdown probability of different material electrodes is approximately the same, and the discharge process is not influenced basically.

(2) Under continuous discharge conditions, due to the heating effect of previous discharges, the surface temperature of tool material with poor thermal conductivity and high specific heat capacity is higher, which makes it easier to cause local discharge breakdown and hence increases breakdown probability. Breakdown probability is influenced by the properties of the materials such as thermal conductivity, specific heat capacity, and density.

(3) The repeatable experimental results of continuous discharges have provided the relationship between breakdown probability and different material properties and also proven the effectiveness of the discharge breakdown probability model.

\section{Conflicts of Interest}

The authors declare that they have no conflicts of interest.

\section{Acknowledgments}

The financial support from the National Natural Science Foundation of China under Grant no. 51405058, Scientific Research Platform Foundation of Liaoning Province under Grant no. JDL2016006, and Talent Special Foundation of Dalian City under Grant no. 2016RQ054 is acknowledged.

\section{References}

[1] R. K. Garg, K. K. Singh, A. Sachdeva, V. S. Sharma, K. Ojha, and S. Singh, "Review of research work in sinking EDM and WEDM on metal matrix composite materials," International Journal of Advanced Manufacturing Technology, vol. 50, no. 5-8, pp. 611-624, 2010.

[2] N. Mohri, N. Saito, Y. Tsunekawa, and N. Kinoshita, "Metal surface modification by electrical discharge machining with composite electrode," CIRP Annals, vol. 42, no. 1, pp. 219-222, 1993.

[3] E. Uhlmann and M. Roehner, "Investigations on reduction of tool electrode wear in micro-EDM using novel electrode materials," CIRP Journal of Manufacturing Science and Technology, vol. 1, no. 2, pp. 92-96, 2008.

[4] M. Cao, Y. Hao, Y. Cao, and S. Yang, "Mechanism and experimental research on small-hole EDM with $\mathrm{Cu}-\mathrm{Cr}$ composite electrode," Sensors \& Transducers, vol. 174, no. 7, pp. 268-272, 2014.
[5] H. C. Tsai, B. H. Yan, and F. Y. Huang, "EDM performance of $\mathrm{Cr} / \mathrm{Cu}$-based composite electrodes," International Journal of Machine Tools and Manufacture, vol. 43, no. 3, pp. 245-252, 2003.

[6] A. K. Khanra, B. R. Sarkar, B. Bhattacharya, L. C. Pathak, and M. M. Godkhindi, "Performance of $\mathrm{ZrB}_{2}$-Cu composite as an EDM electrode," Journal of Materials Processing Technology, vol. 183, no. 1, pp. 122-126, 2007.

[7] T. A. El-Taweel, "Multi-response optimization of EDM with Al-Cu-Si-TiC P/M composite electrode," International Journal of Advanced Manufacturing Technology, vol. 44, no. 1-2, pp. 100-113, 2009.

[8] V. Senthilkumar and M. C. Reddy, "Performance analysis of $\mathrm{Cu}-\mathrm{B}_{4} \mathrm{C}$ metal matrix composite as an EDM electrode," International Journal of Machining and Machinability of Materials, vol. 11, no. 1, pp. 36-50, 2012.

[9] D. Anil and C. Çoğun, "Performance of copper-coated stereo lithographic electrodes with internal cooling channels in electric discharge machining (EDM)," Rapid Prototyping Journal, vol. 14, no. 4, pp. 202-212, 2008.

[10] J. Wang, Y. Wang, F. Zhao et al., "Fabricating electrode by electrodepositing technology and its application in microEDM deep hole drilling," China Mechanical Engineering, vol. 20, no. 15, pp. 1848-1852, 2009, in Chinese.

[11] Q. Lv, Simulation and Experimental Study on the Fabrication of the Composite Electrode for MEDM, Dalian University of Technology, Dalian, China, 2009, in Chinese.

[12] X. P. Li, Y. G. Wang, F. L. Zhao, M. H. Wu, and Y. Liu, "Influence of high frequency pulse on electrode wear in microEDM," Defence Technology, vol. 10, no. 3, pp. 316-320, 2014.

[13] W. Yuangang, Z. Fuling, and W. Jin, "Wear-resist electrodes for micro-EDM," Chinese Journal of Aeronautics, vol. 22, no. 3, pp. 339-342, 2009.

[14] A. H. Chiou, C. C. Tsao, and C. Y. Hsu, "A study of the machining characteristics of micro EDM milling and its improvement by electrode coating," International Journal of Advanced Manufacturing Technology, vol. 78, no. 9-12, pp. 1857-1864, 2015.

[15] J. Jiang and J. Weng, Cathodic Electronics and Gas Discharge Principle, National Defense Industry Press, Beijing, China, 1980, in Chinese.

[16] W. Zhao, Research on the Corrosion of Elecrodes and Its Theory Foundation in EDM, Northwestern Polytechnical University, Xi'an, China, 2003, in Chinese.

[17] B. Izquierdo, J. A. Sanchez, S. Plaza, I. Pombo, and N. Ortega, "A numerical model of the EDM process considering the effect of multiple discharges," International Journal of Machine Tools and Manufacture, vol. 49, no. 3, pp. 220-229, 2009.

[18] The Engineering ToolBox, Specific Heats for Metals, https:// www.engineeringtoolbox.com/specific-heat-metals-d_152.html.

[19] M. Li, Theoretical Basis of Electrical Discharge Machining, National Defense Industry Press, Beijing, China, 1989, in Chinese. 


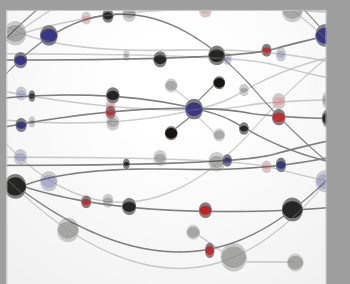

The Scientific World Journal
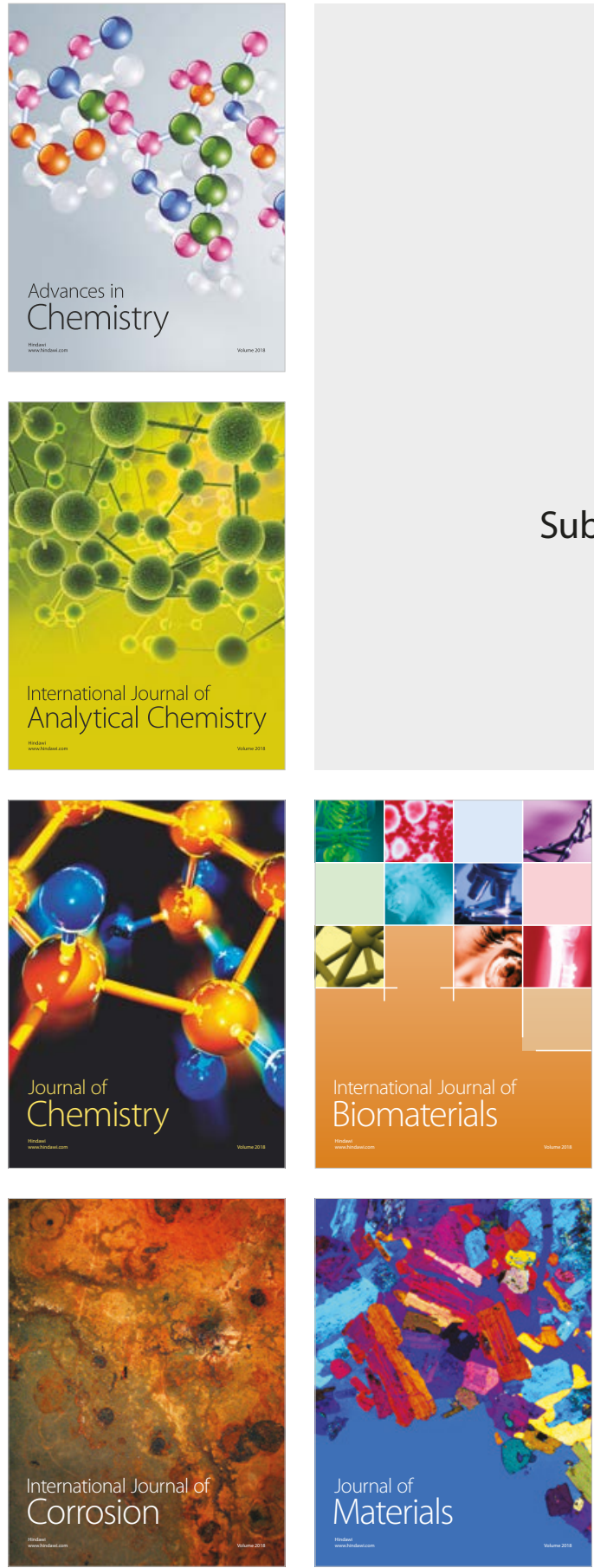

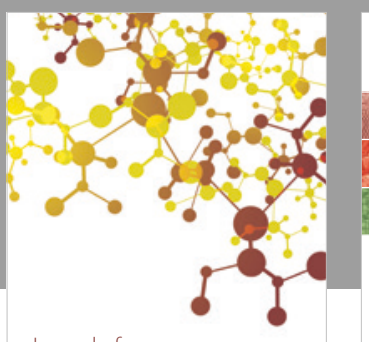

Journal of

Applied Chemistry
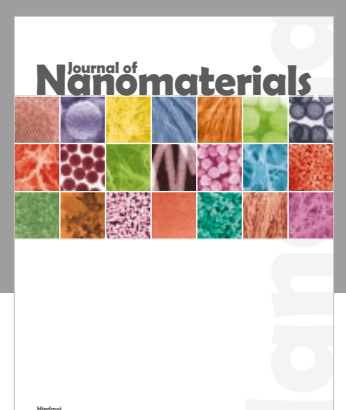

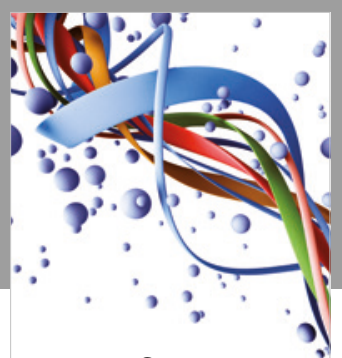

Scientifica

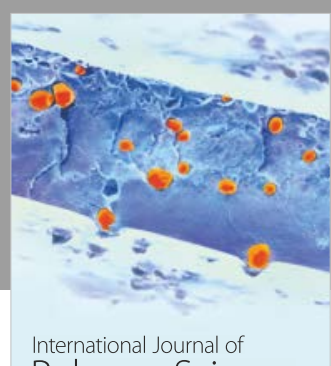

Polymer Science

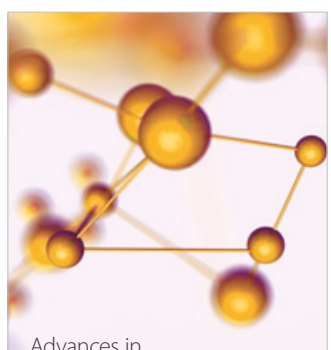

Physical Chemistry
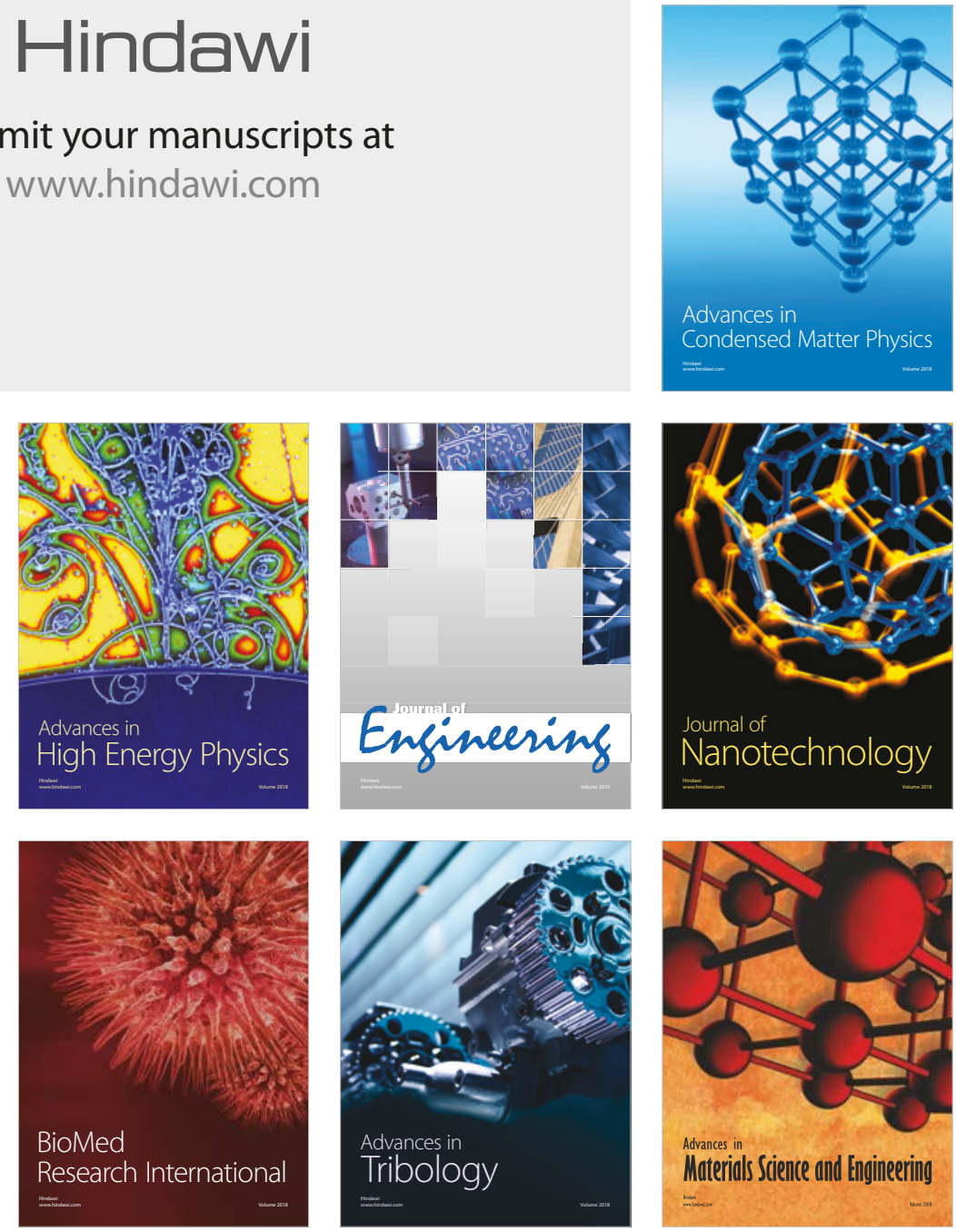